Ana Dili Eğitimi Dergisi
Journal of Mother Tongue Education
ADED - JOMTE
www.anadiliegitimi.com

\title{
Söylemin Düzeyleri: Yapı, Süreç ve Dünya Bilgileri Çerçevesinde Metni Anlamak ${ }^{1}$ Ferhat Ensar*
}

\section{Özet}

Söylemin belli biçimlerinin öğretilmesi açısından deneyim ve açık öğretimin sağladığı kolaylıklar ve bu bağlamda da üstlendiği işlevler konusundaki çalışmalar hakkında yapılmış değerlendirmeler henüz deneysel içerikli bir sonuca kavuşturulamamıştır. Yıllar içerisinde farklı öğretim yaklaşımları farklı sonuçlar vermiştir. Hatta bu yaklaşımlar, değerlendirmelerin farklı uçlarını yansıtmış ve sosyal bir uygulama olarak okur-yazarlıktan bilişsel bir beceri olarak okuryazarlığa kadar birçok farklı kuramsal bakış açısıyla da etkileşmiştir. Metinden anlama sürecindeki deneysel araştırmanın tarihsel geçmişi ve bilişsel bilimin başıca savunuları arasındaki etkileşimin ayrıntılı bir analizinden doğan sonuçlardan hareketle metinlerin gerek yapısal gerekse işlevsel açılardan birtakım düzenlemelerden geçirilmesi önerilmektedir. Bu nedenle, metni kavramanın temel yönlerini anlamada ne tür gelişmeler kaydedildiğini saptamak ve daha az gelişme olan alanlar üzerinde ise ileri araştırmaların nasıl gerçekleştirilmesi gerektiği konusunda zengin çıkarımlara yol açabilecek durumdaki bir işleyişin yöntem bilgilerine başvurmak gerekmektedir. Dolayısıyla bu araştırma örneği çerçevesinde, birincil önemdeki konuların listelenmesi ve kuramsal çerçevenin geçmişten günümüze gelen etkileri bağlamında söz konusu alanlarda ilerleme sağlamanın temel koşulu durumundaki işlem basamaklarının tanıtılması önemli görülmektedir.

Anahtar sözcükler: Zihinsel çıkarımlar, metin kavrama, bellek yapısı, bilgi işleme, metinden öğrenme.

\section{Levels of Discourse: Understanding Text through Structure,Process and World Knowledge}

\begin{abstract}
The contribution of experience and open-teaching in teaching certain types of rhetoric and in this sense, assessment of studies conducted about the functions of experience and openteaching have not yet concluded with an experimental result. In years, different instructional approaches have produced diverse results. Even these approaches have reflected different sides of assessment and interacted with different paradigms including seeing literacy from an social activity to a cognitive skill. Based on the history of experimental studies conducted about understanding from text and the results of analyzing the interactions among various cognitive scientists, it has been suggested to reorganize both the structural and functional perspective of texts. Therefore, determining the developments of the main points for comprehending texts and also deciding how to support the points that are less developed require us to apply to research methods. Thus, the aim of this study is a) to list the primitive topics in text comprehension and b) to lead a discussion including the main steps of text comprehension in order to improve theoretical understanding.
\end{abstract}

Key words: Mental inferences, text comprehension, memory structure, information processing, learning from text.

\footnotetext{
${ }^{1}$ Bu makale Retorik Yapı Kuramının Açıklayıcı Metinler Örneğinde Bir Uygulaması başlıklı doktora tezinden üretilmiştir.

* Yard. Doç. Dr. Yıldız Teknik Üniversitesi, Eğitim Fakültesi, Türkçe Eğitimi Bölümü, İstanbul.
} 
Metinler, öğrenme için önemli araçlardır. Metinleri daha anlaşılır kılma kaygısı, aynı zamanda Türkçe eğitimi alanına özgü işlevsel bir ihtiyacın da doğal yansımasıdır. Diğer yandan faydacı bir bilimsel tutum doğrultusunda öğretici nitelikteki metinlerin birtakım düzeltici stratejiler aracılığıyla geliştirmeye konu edilme düşüncesi, günümüz araştırmacılarının sıklıkla üzerinde odaklandığı bir çalışma konusudur. Ana dili eğitimi çerçevesinde, yazılı metin/söylem yapısının sergilediği görünüm ve buna bağlı olarak da Türkçe eğitiminde öğretici materyal hazırlama ve geliştirme çabalarının bilimsel bir temele kavuşturulabilmesi için daha ileri düzey uzmanlık bilgilerine gereksinim duyulduğu açıktır. Metinden öğrenmenin yapı ve işlev kurgulu modelleri geleneksel olarak ders kitapları, öğretim kılavuzları ve yazılım dokümantasyonlarını oluşturan iki ana metin türüne, bilgilendirici metinler ve amacı bilgilendirmekten daha çok eğlendirme-dinlendirme olan öykü metinlerine odaklanır. Bu metinlerin kesin sınırlarını ve işlem benzerliklerini belirlemenin çoğu durumda imkânsız olduğu bildirilmekteyse de konuyla doğrudan ilgili araştırmalar, bilgilendirici metinlerin temel özelliğinin okuyucuyu bilgilendirmek, daha doğrusu okuyucu bir şeyler öğrenebilsin diye bilgiyi aktarmaktan ibaret olduğunu ortaya koymaktadır. Yine, ilgili literatür bağlamında tanımlanan öykü metinlerinin temel özelliğinin ise hikâye (öykü) anlatmaktan ibaret olduğu ve böylelikle okuyucunun hem eğlendirilebileceği hem de kişisel deneyimlerini farklı metin dünyaları çerçevesinde bir doğrulama sürecine dâhil edebileceği savunulmaktadır (Balcı, 2013: 77-81; Özbay, Bağcı ve Uyar, 2008: 121; Ensar, 2009).

Sözlü ya da yazılı metin üretimi, deneyimlerimizin önemli bir bölümünü oluşturmaktadır. Dolayısıyla, kapsamlı bir 'metin kavrama modeli'ne ilişkin düşünce tarzının incelenip analiz edilebilmesi için metin kavramanın bilişsel modelleri çerçevesindeki bilimsel tartışmalar dikkat çekmektedir (Searle, 2005; Wood, 2003: 75-85). Konuyla ilgili çalışmalarda; metin organizasyonu ve metinden öğrenme kuramlarının genel taslağı, çalışan bellek kapasitesindeki dil işleme ve bireysel farklııklarla doğrudan ilişkili bazı olguları açıklamak için metin kavrama, metin üretimi ve metinden çıkarım süreçleri gibi konu başıkları ön plana çıkmaktadır (Ensar, 2009). Yazılı dili anlama süreci olan okuma eylemi, çoğu araştırmacı tarafından hem 'algısal' hem de 'bilişsel' bir işlem olarak tanımlanmaktadır (Rumelhart, 2004; Just ve Carpenter 1980: 331).

Dilin etkileşimli boyutunu özetler durumdaki sunum çerçeveleri ve söylem dünyalarının dinamik yapısı hakkındaki araştırmaların sonuçları, sağlıktan eğitime eğitimden güvenliğe bütün alanlarda anlama ve problem çözmenin temel malzemesidir. Bu çerçevede, bir söylemdeki bireysel katılımcıların bilgi kaynakları ile onların karşılıkı (ya da özel) veya genel (ya da herkesin bildiği) iletişimleri arasındaki bağı gösteren konuşmacı bilgisi ile dinleyici bilgisi arasındaki örtüşme, aynı zamanda bilgi, önerme ve imge dünyalarının sunumsal bir düzlemde anlaşıımasına da aracılık 
etmektedir. Nitekim mevcut dünya bilgilerinin zihinsel eylemler üzerindeki etkisi, Bartlett (1932, 1950) ile Loftus ve Palmer (1974) gibi araştırmacıların da tanımladığı bir olgudur. Dolayısıyla, anlambilim ve psikodilbilim disiplinleri arasındaki benzerliğe bakıldığında, dildeki sözcüksel ve anlamsal etkenlere yönelik psikodilbilim yaklaşımı, ağılıklı olarak iki önemli düşünceye dayanmaktadır: Kavramsal yönelimli bilgi işleme ve önerme diye adlandırılan zihinsel sunumlar (Ashcraft, 2002: 386).

Sunum etkileşmeleri yoluyla açığa çıkan söylemin düzeyleri üzerine odaklanan dilbilim ve psikoloji kaynaklı çalışmalar, çoğu noktada söylemin önemini "Söylem bizi insan yapandır." nitelemesiyle belirginleştirmeyi amaçlamaktadır (Graesser ve diğerleri., 1997). Dolayısıyla, hem dilbilimde hem de psikolojide söylem ve metin çalışmalarının gün geçtikçe önemi artan ilişkili alanlar hâline gelmesi, bugünün sosyal bilimcileri açısından artık çok da yadırganan bir durum değildir. Bu süreçlerin genel bir değerlendirmesini Dirven (2002) şu şekilde yapmaktadır (Langacker 1995: 4'den aktaran: Dirven, 2002: 80-81):

Tüm dilbilimsel anlam, kavramlaştırmada yatar. Dilbilimsel bir ifade (sözcük, öbek, cümle ya da metin olabilir), kavramsal bir içeriğin bir parçası üzerinde her zaman yorumlama yapar. Düşünülmüş bir olayı tasvir ederken; konuşmacı kapsama dair tercihler yapmalı (ör. Olayın hangi yönlerinin dahil edileceği bilinmelidir) ve olay üzerindeki bakış açısını belirlemelidir. Bakış açısı ise üç unsuru kapsar. İlki, kişinin olaya baktığı bakış noktasını tercih etmeyi içerir. íkincisi, nesnel ve öznel yorumlama arasındaki bir tercihtir. Nesnel yorumlama olayın kesin yeridir (ör. Bundan önce zarfı söz eylem zamanını, şimdi ise objektif bir şekilde zaman referansını tanımlar). Bunun aksine, öznel yorumlama sadece konuşmacı-bağımlı bir referans noktasına işaret eder ("Onu gördüm” geçmiş zaman ifadesindeki olay gibi). Üçüncü olarak, bakış açısı zihinsel taramanın yönünün tercih edilmesini de içerir ("Çatı dik bir şekilde yukarıya doğru eğimli" cümlesi ile "Çatı dik bir şekilde aşağıya doğru eğimli" cümlesi arasındaki zıtlık gibi). İdrak eden kişi (konuşmacı) bu bilişsel süreçlere uygun olarak şeyleri ve ilişkileri seçer ve onları daha geniş bir bileşke biçiminde bağlantılar. Yan cümlecikler, cümleler ve metinler olarak bir araya getirir.

Çoğu araştırmacının da (Lakoff, 1987; Lakoff ve Johnson, 1999) vurguladığı gibi bilişsel dilbilim, Aristotales'ten Descartes'e kadar geleneksel Batı düşüncesine karşı güçlü bir meydan okumadır. Geleneksel düşünce nesnelci gerçekçilik üzerine kuruludur. Bu anlayış çerçevesinde düşünürken kullandığımız semboller sistemi, dış dünyayı doğru bir şekilde temsil ederse dış dünyanın gerçek bilgisi elde edilebilir. Dünyaya alternatif bakış açısı, şekillenmiş gerçekçiliktir. Fenomenal gelenek çerçevesinde bu teori, "Insan dili ve düşüncesi şekillenmiş deneyimlerle yapılandırılır ve bu deneyimlere bağlıdır." görüşünü desteklemektedir. Bu açıdan algısal ve özellikle de uzamsal deneyim, kategorizasyonun önünü açar ve bu somut kategoriler soyut düşünce üzerinde metafor yaratma etkisiyle şekillenir. O halde; din, bilim, metafizik ve felsefeyi de içeren pek çok yaşam alanının 
metaforik seviyede gerçekleşmesi çok da şaşırtıcı bir durum değildir. Çünkü, metaforik teorilerin bağımlı gerektirimleri vardır. Bu da genelleme biçimlerinde ya da doğal kanunlarda tahminler yürütür (Lakoff ve Johnson 1999, s. 103; Lakoff 1987a: 183; Lakoff ve Johnson 1999: 233'den aktaran: Dirven, 2002: 78-80). Bu açılardan, "Dil, toplumsal bir olgudur ve başkaları için var olan pratik bilinçtir. Bilinçle birlikte var olmuş ve onunla karşlıkı etkileşerek gelişmiştir. Nasıl insan toplumunun dışında insan düşüncesi olmazsa öylece insan toplumunun dışında insan dili de olamaz." (Hançerlioğlu, 2002: $62)$.

Metin üretme ve anlama kabiliyetimizin kaynakları konusu, "Söylem İşleme Süreçleri" başlığı altında değişik açılardan ele alınmaktadır. Bu kapsamda Cook ve Myers (2004: 279), "Senaryo Öykülerde Söylem Rollerini İ̧̧leme: Bağlam ve Dünya Bilgisinin Etkileri” başlıklı bir araştırmalarında, “Okuma modellerinin çoğu, anlamsal bilginin bağlamsal bilgiden daha önce bir etkiye sahip olduğunu varsayar" saptamasında bulunarak kendi (şimdiki) çalışmalarının sonuçlarını "daha etkileşimli bir işlemle tutarlı olduğu" biçiminde değerlendirmektedirler. Bu açıdan onlar, bağlamsal bilginin anlamsal bilgi ile birleşerek ön bilginin zihinde işlenmesini kolaylaştırmak için etkileşime girebileceği tezini daha önceki araştırmaların rehberliği çerçevesinde ayrıntılı bir sunumla açıklamaya çalışmakta ve sözcük, sözdizimsel ve söylem seviyeleri açısından gerçekleştirilmiş çalışmaların "(ör. Kaydedilmiş Erişim Modeli [Duffy vd., 1988], Sınırlama Modeli [McDonald ve diğerleri., 1994], Hafıza Kaynaklı Metin İşleme Görüşü [2000; Gerrig ve McKoon, 1998; Myers ve O’Brien, 1998; O’Brien, Cook ve Derepentigny, 2001; Rizzella ve O'Brien, 2002])" sonuçlarından hareketle kendi bildirimlerinin de bilgi işlemeyi tanımlamak için daha önceden yapılmış olan değerlendirmelerle uyumlu olduğunu savunmaktadırlar (268-269):

Söylem bağlamı, bir metindeki bir sözcüğün kavranmasını sözcüksel erişimi kolaylaştırarak ya da önceki metinle hedef kavramın birleşimini kolaylaştırarak etkileyebilir. İki deneyde de bağlamsal etkiyi senaryo öykülerde incelemek için gözle izlenecek ölçüler kullandık. Söz konusu deneylerde bağlam, rol doldurucuların birleşimi üzerinde ilk etkiye sahiptir. Sonuçlar okuma üzerinde bağlamsal etkinin birkaç teorisi bakımından tartışılır. Bilgi iki aşamalı işleme modelini destekler gibi görünür: Birinci aşamada metin aktif hafızanın kavramlarına bağlanır; ikinci aşamada ise eski ve yeni bilgi arasındaki bilgi değerlendirilir.

Anlatı söylemi ve olay yapısı kavramı gibi başıklara dilbilimci ve bilişsel psikologların çalışmalarında sıklıkla yer verilmektedir (ör. Labov, 1972; van Dijk, 1980). Örneğin, doğal olay yapısının bütün bileşenlerini içeren anlatı şemasının 9-10 yaşlarında kurulduğunu gösteren sözlü anlatı söylemi üzerine birçok çalışma "(ör. Berman ve Slobin, 1994; Hickmann, 1995; Jisa, 2004 [resimli bir hikâye kitabıyla ilgili], Karmiloff-Smith, 1983 [resim serisiyle ilgili], Peterson ve McCabe, 1983 [kişisel deneyim hikâyeleriyle ilgili])” bulunmaktadır (Berman ve Nir-sagiv, B, 2007: 80). Metin 
yapısının incelenmesi konusundaki çalışmalara dünya bilgisi ile süreçler boyutu gibi alt başıkların eklenmiş olması, metni anlama konusunda yeni ve ilginç bir bakış açısı sağlamakla kalmamış diğer yandan da metin/söylem çözümlemesinin kullanılabilir yeni imkânlarını da beraberinde getirmiştir. Örneğin Britton, Kieras, Voss, Bisanz, Graesser, Goodman ve Miller gibi araştırmacılar, açıklayıcı metni anlamlandırmak doğrultusunda yapı, süreç ve dünya bilgisi işleme yaklaşımlarını "açıklayıcı metindeki konuya ait ifadeleri ortaya çıkarmak, metin işlemenin sınırlı çalışan bellekte nasıl gerçekleştirildiğini tanımlamak ve açıklayıcı metni anlayabilmek için gereken çıkarımları yapmayı kolaylaştıran dünya bilgisini araştırmak" gibi alt başıklar açısından sınamışlardır. Özellikle de Voss ve Bisanz, metinde ele alınan uzmanlık alanı hakkında (ör. beyzbol) çok fazla ya da çok az bilgiye sahip olmanın metni anlama üzerindeki etkisini incelemiştir. Graesser ve Goodman ise okuyucunun metnin tutarlı bir zihinsel betimlemesini yapılandırabilmesi için gerekli olan çıkarımları yapabilmesini sağlamak amacıyla tasarlanan soruların nasıl kullanabileceğini tanımlamıştır. Miller ise dünya bilgisinin okuma esnasında metnin zihinsel betimlemesini oluşturabilmek için gerekli olan çıkarımların yapılabilmesi açısından nasıl kullanıldı̆ııı açıklamıştır. Miller'in düşüncesi, aslında Kintsch (1974) tarafından başlatılan metni anlama araştırması süreci için son derece ileri aşama örneklerden birisidir. Miller'in bu araştırması, ilk safhalarında metnin yapısına, yani metnin tutarlı bir grafiğini içeren yaygın referanslarla bağlantılı olan önermeler ağına odaklanmıştır. Sonrasında ise metni anlamak için gerekli olan genel kültürü ve metinleri analiz etmek için bu girdinin (genel kültür) nasıl kullanıldığını açıklamaya çalışmaktadır (Britton ve Black, 1985: 5-7).

Metni anlamanın üç boyutu hakkındaki araştırmalar; yani yapı, genel kültür ve süreç bileşenleri, metinden öğrenme süreçleri çerçevesindeki gelişmeleri ve buna bağlı olarak da gündemdeki işlem değişikliklerini açıklamaktadır. Dolayısıyla metinden öğrenmenin tam bir açıklaması, metinleri anlama ve daha sonra hatırlamayı kolaylaştıran işlemleri betimleyen modeller oluşturarak söz konusu metin ve dünya bilgilerinden etkilenen zihinsel süreçlerin de tanımlanmasını gerektirmektedir. Örneğin bu açıdan tanımlanması gereken çeşitli süreçleri betimlemek amacıyla Kintsch ve van Dijk (1978), çalışan bellekteki anlam birimlerini birleştiren zihinsel kaynakların okuma boyunca nasıl tahsis edildiğini saptamaya çalışmışlardır. Yine Britton, Glynn, Meyer ve Penland (1982) ile Graesser, Hoffman ve Clark (1980) gibi araştırmacılar, metindeki bilgileri süzmek ve ayırmak için bilgi yapılarını andıran ve etkili hatırlama için bilgi organize edicileri de içeren bir dizi süreci tanımlamaya çalışmışlardır (Britton ve Black, 1985: 5). 


\section{Sonuç}

Metinden öğrenme süreçleri konusunda yapılmış araştırmaların, bugüne kadar tek başına uygulanabilir bir alternatif sağlayamamış olması durumu dikkate alındığında, böylesi bir alternatifin çok yönlü ve disiplinler arası uzantıları içerir nitelikteki bir bilgi ağına gönderimde bulunacağı çıkarımını yapmak mümkün olmaktadır. Ayrıca, söz konusu durum çerçevesinde sayısız tartışmaların yapılmış ve yapılmakta olduğu da ilgili literatür aracılığıyla gözlemlenmektedir. Örneğin, bunca tartışmalara karşın konuşmanın doğası ve süreçleri hakkında diğer alan bildirimlerinden bağımsız varsayımlar geliştirilememektedir. Dolayısıyla cevaplanmayı bekleyen bir dizi soru, günümüz araştırmacılarının disiplinler arası yaklaşımlar başlığı altında inceleyebilecekleri türden sorulardandır.

\section{Kaynakça}

Ashcraft, M.H. (2002). Cognition (3rd Ed.). NJ: Prentice Hall.

Balcı, A. (2013). Okuma ve Anlama Eğitimi. Ankara: Pegem Akademi Yayıncılık.

Bartlett, F.C. (1950). Remembering: A study in experimental and social psychology. Cambridge, Eng.: The University Press (Reprented).

Berman, R.A. \& Nir-sagiv, B. (2007). Comparing Narrative and Expository Text Construction Across Adolescence: A Developmental Paradox. Discourse Processes, 43 (2), 79-120.

Britton, B.K. \& Black, J.B. (1985). Understanding expository text: From structure to process and world knowledge. In B.K. Britton \& J.B. Black (Eds.). Understanding expository text: A theoretical and practical handbook for analyzing explanatory text. Hillsdale, NJ: Erlbaum.

Britton, B.K., Glynn, S.M., Meyer, B.J.F. \& Penland, M.J. (1982). Effects of text structure on use of cognitive capacity during reading. Journal of Educational Psychology, 74, 51-61.

Cook, A.E. \& Myers, J.L. (2004). Processing discourse roles in scripted narratives: the influences of context world knowledge. Journal of Memory and Language, (50), 268-288.

Dirven, René (2002). Cognitive Linguistics. In. The Linguistics Encylopedia (Second Edition). Kırsten Malmkjær (edt.). NY: Routledge.

Ensar, F. (2009). Retorik Yapı Kuramının Açıklayıcı Metinler Örneğinde Bir Uygulaması. Gazi Üniversitesi Eğitim Bilimleri Enstitüsü Türkçe Eğitimi Ana Bilim Dalı Yayımlanmamış Doktora Tezi, Ankara.

Graesser, A.C., Hoffman, N.L. \& Clark, L.F. (1980). Structural components of reading time. Journal of Verbal Learning and Verbal Behavior,19, 135-51.

Hançerlioğlu, O. (2002). Felsefe Sözlüğü. Remzi Kitabevi.

Just, M.A. \& Carpenter, P. (1992). A capacity theory of comprehension: Individual differences in working memory. Psychological Review, 99, 122-149.

Just, M.A. \& Carpenter, P.A. (1980). A theory of reading: From eye fixations to comprehension. Psychological Review, 87, 329-354. 


\section{Söylemin Düzeyleri: Yapı, Süreç ve Dünya Bilgileri Çerçevesinde Metni Anlamak}

Kintsch, W. (1974). The Represantation of Meaning in Memory. Hillsdale, NJ: LEA.

Kintsch, W. (1988). The use of knowledge in discourse processing: A Construction-Integration model. Psychological Review, 95, 163-182.

Kintsch, W. \& Van Dijk, T.A. (1978). Toward A Model of Text Comprehension and Production. Psychological Review, 85, 363-94.

Labov, W. (1972). Language in the inner city. Philadelphia: University of Pennsylvania Press.

Loftus, E.F. \& Palmer, J.C. (1974). Reconstruction of automobile destruction: An example of the interaction between language and memory. Journal of Verbal Learning and Verbal Behavior, 13, 585-589.

Lorch, R.F. \& van Den Broek, P. (1997). Understrstanding reading comprehension: Current and future contributions of cognitive science. Contemporary Educational Psychology, (22). 213-246.

MacDonald, M.C. \& Christiansen, M.H. (2002). Reassessing working memory: Comment on Just and Carpenter (1992) and Waters and Caplan (1996). Psychological Review, (109), 1, 35-54.

Mannes, S.M. \& Kintsch, W. (1987). Knowledge organization and text organization. Cognition and Instruction, $4(2), 91-115$

Mckoon, G. \& Ratcliff, R. (1992). Inference during reading. Psychological Review, 99, 440-466.

Özbay, M., Bağcı, H. ve Uyar, Y. (2008). Türkçe Öğretmeni Adaylarının Okuma Tutumlarının Çeşitli Değişkenlere Göre Değerlendirilmesi. Inönü Üniversitesi Eğitim Fakültesi Dergisi, (9), 15, 117-136.

Rumelhart, D. E. (2004). Toward an interactive model of reading. In Robert B. Ruddell et al. (Eds.). Theoretical Models And Processes Of Reading, (Fifth Edition): International Reading Association, Newark, DE.

Searle, J. (2005). Akıllar, Beyinler ve Bilim. (Çev., Kemal Bek). İstanbul: Say Yayınları.

van Dijk, T. A. (1980). Macrostructures. Hillsdale, NJ: Lawrence Erlbaum Associates, Inc.

Waters, G.S. \& Caplan, D. (1996). The capacity theory of sentence comprehension: Critique of Just and Carpenter (1992). Psychological Review, 103, 761-772.

Wood, D. (2003). Çocuklarda düşünme ve öğrenme (Çev., Mine Özünlü). Doruk Yayıncılık. 